\title{
Cigarette smoking is associated with high level of ferroptosis in seminal plasma and affects semen quality
}

\author{
Zhanhui Ou', Qirong Wen², Yu Deng ${ }^{1}$, Yang Yu', Zhiheng Chen ${ }^{1}$ and Ling Sun ${ }^{*}$
}

\begin{abstract}
Purpose: The effects of cigarette smoking on male semen quality are controversial, and the molecular mechanisms underlying how cigarette smoking affects semen quality are not clear yet.

Methods: In this study, semen samples from 70 heavy smokers and 75 non-smokers receiving infertility treatment were included. Basic semen parameters in non-smokers and heavy smokers were evaluated. Levels of glutathione (GSH), lipid reactive oxygen species (ROS), iron and GSH-dependent peroxidase 4 (GPX4) protein level were observed in human seminal plasma and in GC-2Spd cells exposed to cigarette smoke condensate (CSC).

Results: Heavy smokers had significantly higher abnormalities (sperm viability and sperm progressive motility) than non-smoking counterparts. Comparing non-smokers group, GSH level was reduced in the group of heavy smokers $(P<0.05)$. However, the level of lipid ROS and iron were significantly increased $(P<0.05)$. Besides, GSH level was reduced following treatment with CSC for $24 \mathrm{~h}$, while lipid ROS and iron levels were increased $(P<0.05)$. However, the levels were reduced after being co-cultured with Ferrostatin-1 (Fer-1) $(P<0.05)$. The level of GPX4 protein was reduced after being treated with CSC in $24 \mathrm{~h}$, and increased after being co-cultured with Fer-1 $(P<0.05)$.
\end{abstract}

Conclusion: Cigarette smoking is associated with high level of ferroptosis in seminal plasma and affect semen quality.

Keywords: Ferroptosis, Cigarette smoking, Semen quality, Cigarette smoke condensate, Infertility

\section{Introduction}

Infertility affects $10-15 \%$ of couples worldwide and has become a public health problem in recent years [1]. Male infertility accounts for approximately half of these problems, and decreased semen quality has been widely reported in recent years $[2,3]$. The most common cause of male infertility is defective sperm function, which may be affected by genetic disorders, genital tract infections, medical interventions, environmental contamination. Cigarette smoking is also considered to be a risk to male

\footnotetext{
*Correspondence: sunling6299@163.com

'Center of Reproductive Medicine, Guangzhou Women and Children's

Medical Center, Guangzhou Medical University, 510623, Guangzhou, Guangdong, P.R. China

Full list of author information is available at the end of the article
}

infertility as it could be directly and indirectly toxic to spermatogenesis [4-6]. Even though the reason for the decline of semen quality remains unknown, the correlation between smoking and semen quality has been reported in many studies [7-11]. However, the effect of cigarette smoking on sperm quality reported by some studies was shown to be limited [12, 13]. Therefore, the effect of cigarette smoking on semen quality and its mechanism needs to be clarified.

Cigarette smoke contains high concentrations of nitric oxide, peroxynitrite, and free radicals which can potentially induce the production of cellular reactive oxygen species (ROS) in the human body $[14,15]$. Thus, this might be the main reason for the decreased semen 
quality caused by cigarette smoking, as some studies have also reported $[4,16]$. Moreover, it has also been reported that the basic semen parameters could be influenced by cigarette smoking [17-19]. Based on these findings, we believe that cigarette smoking could impair the sperm quality, but what is its potential mechanism?

Ferroptosis is an identified and non-apoptotic regulated cell death with dependency of iron and lipotoxicity, which is firstly observed in cancer cells with oncogenic Ras mutation and could be induced by erastin [20]. Ferroptosis occurs depending on the process of lipid peroxidation activated by non-enzymatic (Feton reactions) and enzymatic mechanism (lipoxygenases) [21]. It is characterized by a production of reactive oxygen species from accumulated iron and lipid peroxidation [22]. Ferroptosis can be induced in the classic way of the inactivation of GPX4, which is the major protector of cellular peroxidation damage [23]. One of the main mechanisms of inactivation of GPX4 is the deprivation of glutathione (GSH) [23]. It can be said that the likelihood of ferroptosis is determined by the balance between ROS production and peroxidation-antioxidant system [24]. This imbalance can result in a number of diseases, including hemochromatosis, neurotoxicity, cancer, liver injury and so on [22, 25-27]. Furthermore, Li et al. showed ferroptosis was a pervasive and dynamic type of cell death induced by oxygen-glucose deprivation and reoxygenation injury in Sertoli cells [22, 25-27], Bromfield also showed oxidative stress induces ferroptosis in spermatids [28]. In summary, we hypothesize that cigarette smoke might reduce the semen quality via the inducing lipid peroxidation and the further occurrence of ferroptosis.

In this study, we first collected the semen samples from heavy smokers and non-smokers and evaluated the semen quality via comparing the parameters. Moreover, the occurrence of ferroptosis was also detected in seminal plasma and GC-2spd cell line after the treatment of cigarette smoke condensate, while also detecting the level of GPX4 in the GC-2spd cell, which is the key regulator of ferroptosis. We aim to find out the potential mechanism of the sperm impairment caused by cigarette smoking.

\section{Materials and methods \\ Study subjects}

This study was declared exempt by the ethics committee of the Guangzhou Women and Children's Medical Center. All studies involving human subjects were conducted in accordance with guidelines laid down in the Declaration of Helsinki. Written informed consents were obtained by the participants, and the subjects' data on medical history, lifestyle, and smoking status with a structured questionnaire were collected. Individuals who had never smoked were defined as non-smokers. Current smokers with smoking dose more than 1 pack per day over 10 years or smoking dose more than 2 packs per day over 5 years were defined as heavy smokers. They were men who visited the reproductive medicine center in the Guangzhou Women and Children's Medical Center for infertility treatment during March 2017 to December 2017. Non-smokers were randomly selected from patients who were agematched to heavy smokers. All subjects underwent physical examinations and at least two semen analyses. Men who were unhealthy or had a known cause of defective spermatogenesis, such as varicocele, infection, obstruction of the vas deferens, chromosomal abnormalities, or microdeletions of the azoospermia factor region on the $\mathrm{Y}$ chromosome were excluded. Patients who were diagnosed with azoospermia, severe oligozoospermia (sperm concentration $<5^{*} 10^{6}$ cells $/ \mathrm{mL}$ ), hemospermia, leukospermia, and necrozoospermia were also excluded. Finally, 70 heavy smokers and 75 non-smokers were recruited.

\section{Semen collection and analysis}

Semen samples were collected in sterile containers from patients by masturbation after 2-7 days of sexual abstinence. Samples were allowed to liquefy for at least $30 \mathrm{~min}$ at room temperature. Analysis of semen volume, $\mathrm{pH}$, sperm concentration, motility, vitality, sperm morphology, and computer-assisted semen analysis were carried out according to WHO guidelines [29]. Samples were centrifuged at $1000 * 3 \mathrm{~g}$ for $10 \mathrm{~min}$, and seminal plasma and cell pellets were separated and stored at $80^{\circ} \mathrm{C}$ until analysis.

\section{Cell culture and cigarette smoke condensate treatment}

GC-2spd cell lines were purchased from the American Tissue Culture Collection (ATCC) and maintained in Dulbecco modified Eagles media (DMEM, Gibco, USA) supplemented with heat-inactivated $10 \%$ fetal bovine serum (Biological Industries, Israel) in a $95 \%$ airhumidified incubator with $5 \% \mathrm{CO}_{2}$ at $37^{\circ} \mathrm{C}$ as our previous study [30].

Cigarette smoke condensate (CSC) was prepared according to the study [31] and resuspended at a concentration of $50 \mathrm{mg} / \mathrm{mL}$ in dimethyl sulfoxide (DMSO) as stock solution. For smoke-exposure experiments, cells were cultured in medium with $400 \mu \mathrm{g} / \mathrm{mL}$ of CSC (after treated with $0-800 \mu \mathrm{g} / \mathrm{mL}$ of CSC for $24 \mathrm{~h}$ ). After exposure to CSC for $24 \mathrm{~h}$, cells were used for further study.

\section{Cell viability assay}

Cell viability was determined with a Cell Counting Kit-8 (CCK-8) assay. Briefly, cells were plated at a density of $5 \times 10^{4}$ cells/well in a 96-well plate with $100 \mu \mathrm{l}$ of 
medium. Following treatment, cell viability was evaluated with CCK- 8 according to manufacturer's instructions, and absorbance was measured at $450 \mathrm{~nm}$ with a microplate reader. Cell viability was expressed as the percentage of live cells vs. controls (set at 100\%).

\section{Iron assay}

The relative iron concentration in cell lysates was assessed using the Iron Assay Kit (no. ab83366; Abcam) according to the manufacturer's instructions and our previous study [32].

\section{Lipid peroxidation assay}

The relative malondialdehyde (MDA) concentration in cell lysates was assessed using a Lipid Peroxidation (MDA) Assay Kit (no. ab118970; Abcam) according to the manufacturer's instructions.

\section{Glutathione assay}

The relative glutathione (GSH) concentration in cell lysates was assessed using the Glutathione Assay Kit (no. CS0260; Sigma) according to the manufacturer's instructions.

\section{Western blot analysis}

Following treatment, cells were washed twice with cold PBS and extracted with RIPA lysis buffer on ice. Extracted cells were then sonicated and centrifuged at $15,000 \mathrm{~g}$ for five minutes. Protein extraction was carried out in accordance with existing protocols (Beyotime, China). Protein content was determined using a BCA protein assay kit, according to manufacturer's instructions. Equivalent amounts of protein were separated on 10-15\% SDS-polyacrylamide gels and blotted onto a nitrocellulose membrane. After blocking at room temperature for two hours with $5 \%$ non-fat milk in TBS with $0.1 \%$ Tween-20, membranes were probed with GPX4 (1:5000 dilution), GAPDH (1:5000 dilution) and HRP conjugated IgG antibodies (1:10,000 dilution); and visualized by exposure to Gel Doc XR (BioRad, USA). Relative band intensity was then determined by standard scanning densitometry normalized with GAPDH.

\section{Statistical analysis}

The independent sample t-test was used to analyze numerical data in two groups. The nonparametric Mann-Whitney test was used to analyze differences between nonhomogeneous variances. One-way ANOVA with Tukey post-test was used to analyze data in multiple groups (Cell viability, GSH, lipid ROS and iron level in the GC-2spd cells) (SPSS version 17.0 for Windows). A two-sided $P$ value of 0.05 was considered statistically significant.

\section{Results}

\section{Semen parameters of study subjects}

The mean age and semen parameters of 75 non-smokers and 70 heavy smokers are given in Table 1. The two groups had similar average age (34.4 years vs. 35.8 years). The sperm vitality ( $65.4 \%$ vs. $59.4 \%)$, and sperm progressive motility ( $45.5 \%$ vs. $36.9 \%)$ between the two groups were significantly different $(P<0.05)$, but other basic semen parameters, including sperm concentration $(64.6$ ${ }^{*} 10^{6} / \mathrm{mL}$ vs. $\left.56.5 * 10^{6} / \mathrm{mL}\right)$, semen volume $(3.2 \mathrm{~mL}$ vs. $3.2 \mathrm{~mL}$ ), abnormal sperm morphology (95.1\% vs. 96.1\%), and sperm counts $\left(216.5 * 10^{6}\right.$ ells vs. $189.6 * 10^{6}$ cells $)$ were not significantly different $(P>0.05)$ (Table 1$)$.

\section{Seminal plasma GSH, lipid ROS and iron level}

To investigate the ferroptosis level between non-smokers and heavy smokers, GSH, lipid ROS and iron level were detected in the seminal plasma. Comparing non-smokers group, GSH level was reduced in the group of heavy smokers $(P<0.05)$. However, the level of lipid ROS and iron were increased $(\mathrm{P}<0.05)$ (Fig. 1a, b, c). Collectively, these indicated that ferroptosis level was increased in the seminal plasma of heavy smokers.

\section{Cell death level in GC-2spd cells after CSC treatment}

The effect of CSC on the viability of GC-2spd cells was investigated using the CCK- 8 assay. Cell viability was reduced in a dose-dependent manner following treatment with CSC in $24 \mathrm{~h}$ (Fig. 2a). To determine whether CSC-induced toxicity was caused by apoptosis or/and ferroptosis independent, Z-VAD-fmk (a broad caspase spectrum inhibitor) and Ferrostatin-1 (Fer-1, an ferroptosis inhibiter) were co-culture with CSC. And the level of CSC-induced toxicity was reduced, but still not totally inhibited by the co-treatment of Z-VAD-fmk $(P<0.05)$. Next, Ferrostatin-1 and Z-VAD-fmk were co-culture with CSC. The level of CSC-induced toxicity was reduced dramatically $(P<0.01)$ (Fig. $2 b)$.

Table 1 The semen parameters of 75 non-smokers and 70 heavy smokers

\begin{tabular}{llll}
\hline Parameter & Non-smokers & Heavy smokers & $P$ \\
\hline $\mathrm{N}$ & 75 & 70 & \\
Age $(\mathrm{y})$ & $34.4 \pm 5.7$ & $35.8 \pm 4.5$ & 0.101 \\
Sperm volume $(\mathrm{mL})$ & $3.2 \pm 1.1$ & $3.2 \pm 1.2$ & 0.836 \\
Sperm concentration $\left(\mathrm{X} 10^{6}\right)$ & $64.6 \pm 15.6$ & $56.5 \pm 35.4$ & 0.081 \\
Sperm count $\left(\mathrm{X} 10^{6}\right.$ cells/mL) & $216.5 \pm 134.3$ & $189.6 \pm 152.5$ & 0.262 \\
Sperm progressive motility (\%) & $45.5 \pm 12.2$ & $36.9 \pm 15.7$ & 0.000 \\
Abnormal sperm morphology (\%) & $95.1 \pm 3.2$ & $96.1 \pm 1.8$ & 0.230 \\
Sperm vitality (\%) & $65.4 \pm 14.8$ & $59.4 \pm 17.9$ & 0.029 \\
\hline
\end{tabular}

Note: Data are presented as mean \pm SD 


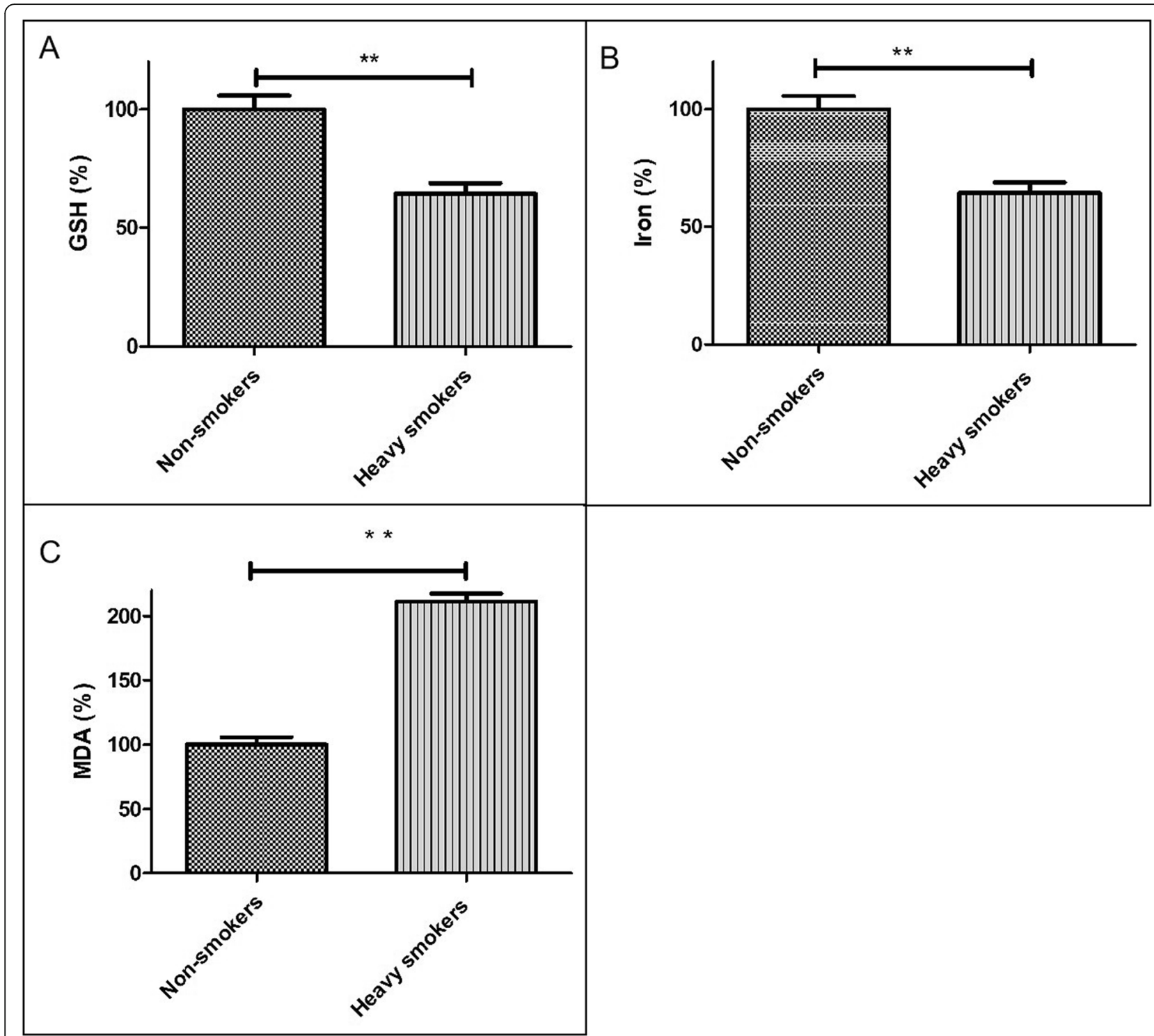

Fig. 1 Seminal GSH, lipid ROS and iron level in non-smokers and heavy smokers. a GSH level in the semen of non-smokers and heavy smokers. $\mathbf{b}$ Iron level in the semen of non-smokers and heavy smokers. $\mathbf{c}$ Lipid ROS level in the semen of non-smokers and heavy smokers. ${ }^{*} P<0.05$, ${ }^{* *} P<$ 0.01 represents the statistical difference compared to the respective group $(n=3)$

\section{Ferroptosis level in GC-2spd cells after CSC treatment}

To investigate the ferroptosis level induced by CSC in the GC-2spd cells, GSH, lipid ROS and iron level were measured. GSH level was reduced following treatment with CSC in $24 \mathrm{~h}$, and lipid ROS and iron level were increased $(P<0.05)$. However, the level of them were reduced after co-cultured with Fer-1 $(\mathrm{P}<0.05)$ (Fig. 3a, b, c). Besides, the level of GPX4 protein was reduced after treating with $\mathrm{CSC}$ for $24 \mathrm{~h}$, and restored after the cells were treated with CSC and Fer-1 $(\mathrm{P}<0.05)$ (Fig. 3d, e). According to these results, CSC-induced toxicity in the GC-2spd cells was also contributed by ferroptosis.

\section{Discussion}

Although cigarette smoking is considered as a major risk factor for several human diseases, such as lung cancer and chronic obstructive pulmonary disease (COPD) [33, 34 , the effects of smoking on male infertility are controversial. Some studies have reported that cigarette smoking could significantly decrease basic semen parameters [17-19], whereas other studies had shown that cigarette smoking did not affect semen quality [14, 15]. In the present work, a case-control study was conducted between heavy smokers and non-smokers, the results showed that sperm vitality, and sperm progressive motility between the two groups were significantly different. 


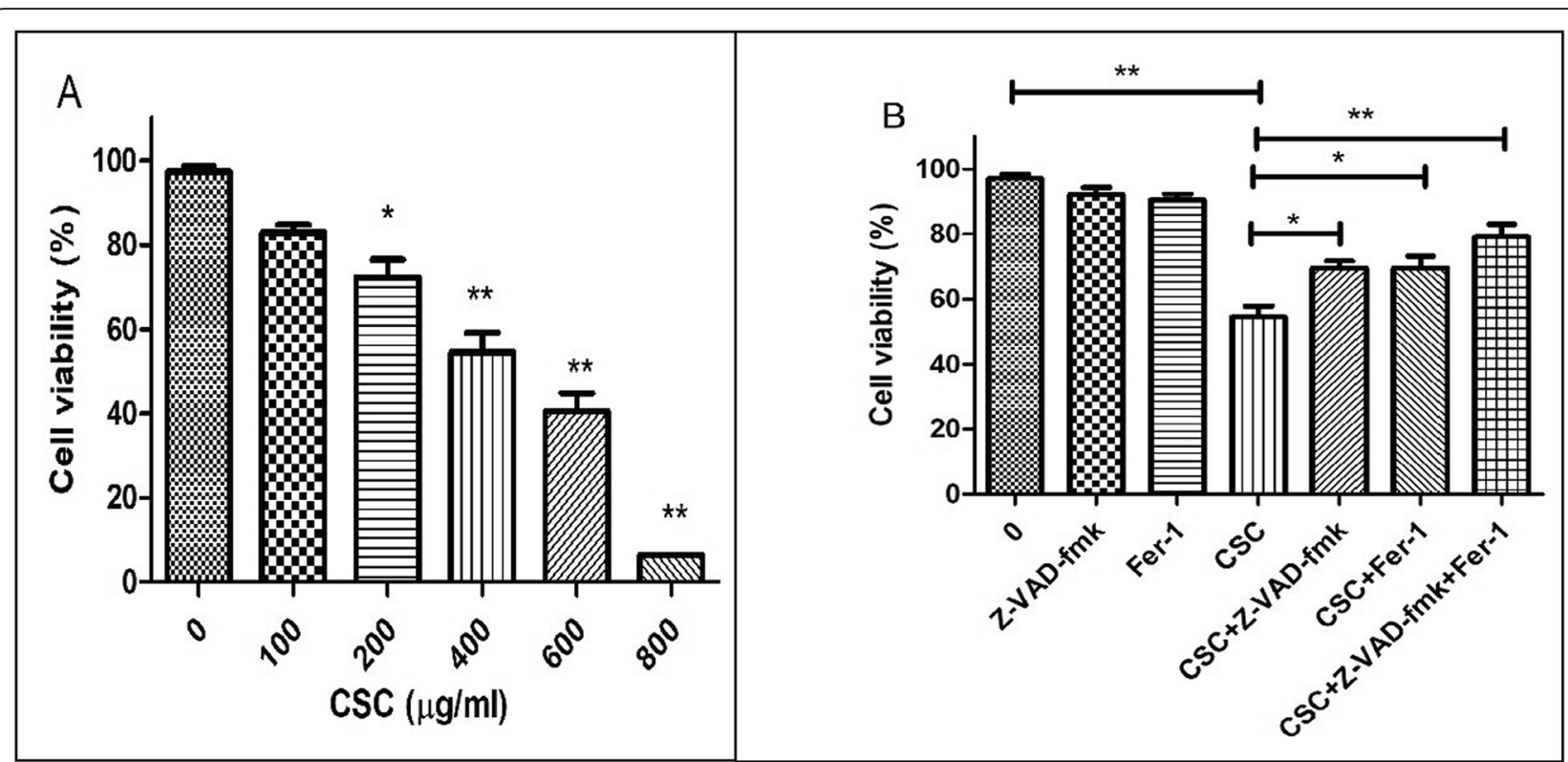

Fig. 2 Exposure to CSC-triggered cell death in GC-2spd cells. a GC-2spd cells were treated with $0-800 \mu \mathrm{g} / \mathrm{mL}$ of CSC for $24 \mathrm{~h}$. Cell viability was measured by CCK-8 assay $(n=3)$. b The viability of GC-2spd cells were detected after treatment with $400 \mu \mathrm{g} / \mathrm{mL}$ of CSC, we also detected the cellular viability after the treatment with Fer-1 and Z-VAD-fmk to eliminate their cytotoxicity. And the cellular viability following pre-incubation with $400 \mu \mathrm{g} / \mathrm{mL}$ of CSC plus $10 \mu \mathrm{mol} / \mathrm{L}$ of Fer-1, Z-VAD-fmk and Fer-1 combined with Z-VAD-fmk for $24 \mathrm{~h}$ was detected respectively. ${ }^{* P}<$ 0.05 , $* * 0.01$ represents the statistical difference compared to the respective group $(n=3)$

The sperm quality was lower in the group of heavy smokers.

The molecular mechanisms' underlying smoking-affect semen quality are not clear yet. Smoking has been demonstrated to increase DNA fragmentation and damage in sperm mainly by inducing apoptosis $[35,36]$. Caspaseindependent apoptosis resulted from oxidative stress mediates this process. However, this mechanism is not solely responsible for affecting semen quality in heavy smokers.

Ferroptosis, a new regulated cell death identified by Brent R. Stockwell's lab in 2012, is mediated by an iron dependent accumulation of lipid reactive oxygen species (ROS). Study by Li et al. showed that ferroptosis is a pervasive and dynamic type of cell death induced by Oxygen-glucose deprivation and reoxygenation injury in Sertoli cells [37], Elizabeth G explored the contribution of ferroptosis to the demise of germline cells during periods of acute stress in vivo [28]. Previous studies have verified that the lethal lipid peroxidation reaction is accelerated by intracellular iron in the germ cells, whereas other divalent cationic metals have no effect $[38,39]$.

Based on these discoveries, we present the first findings of ferroptosis in the seminal plasma from heavy smokers. In this study, we found that GSH level was reduced in the group of heavy smokers. However, the level of lipid ROS and iron were increased. These results indicate that the ferroptosis level was increased in the seminal plasma of heavy smokers. For the further proof that the effect on semen quality of heavy smokers by ferroptosis, GC-2spd cell line was adopted in this study. After the cell was treated with CSC, the cellular lipid ROS and iron level increased and level of GSH dropped. Fer-1 acts as a lipid ROS scavenger and suppresses ferroptosis specifically [22, 40], and it was usually used as a protector of resisting ferroptosis. According to the results, Fer-1 significantly depressed the cell death and lipid ROS generation caused by CSC in GC-2spd cells, this indicated that lipid peroxidation might be involved in CSC-induced cell death. Besides, the level of GPX4 protein, which is the protector of ferroptosis, was also found to be downregulated in GC-2spd cell after the cells were treated with CSC. However, level of GPX4 could be restored by treating the cells with CSC and Fer-1 simutaneously. Based on these findings, CSCinduced toxicity in the GC-2spd cells was also contributed by ferroptosis. This indicates that smoking is associated with abnormalities of human semen because the ferroptosis induced by lipid peroxidation. The major factors regulating ferroptosis are lipid peroxidation and iron metabolism signaling [21, 22]. Two mechanisms maybe responsible for inducing ferroptosis: (1) the indirect way of inhibiting GSH via the deprivation of the precursor Cys (cystine), as a result of the subsequent influence on the system $\mathrm{xc}^{-}$, and (2) inactivating GPX4 

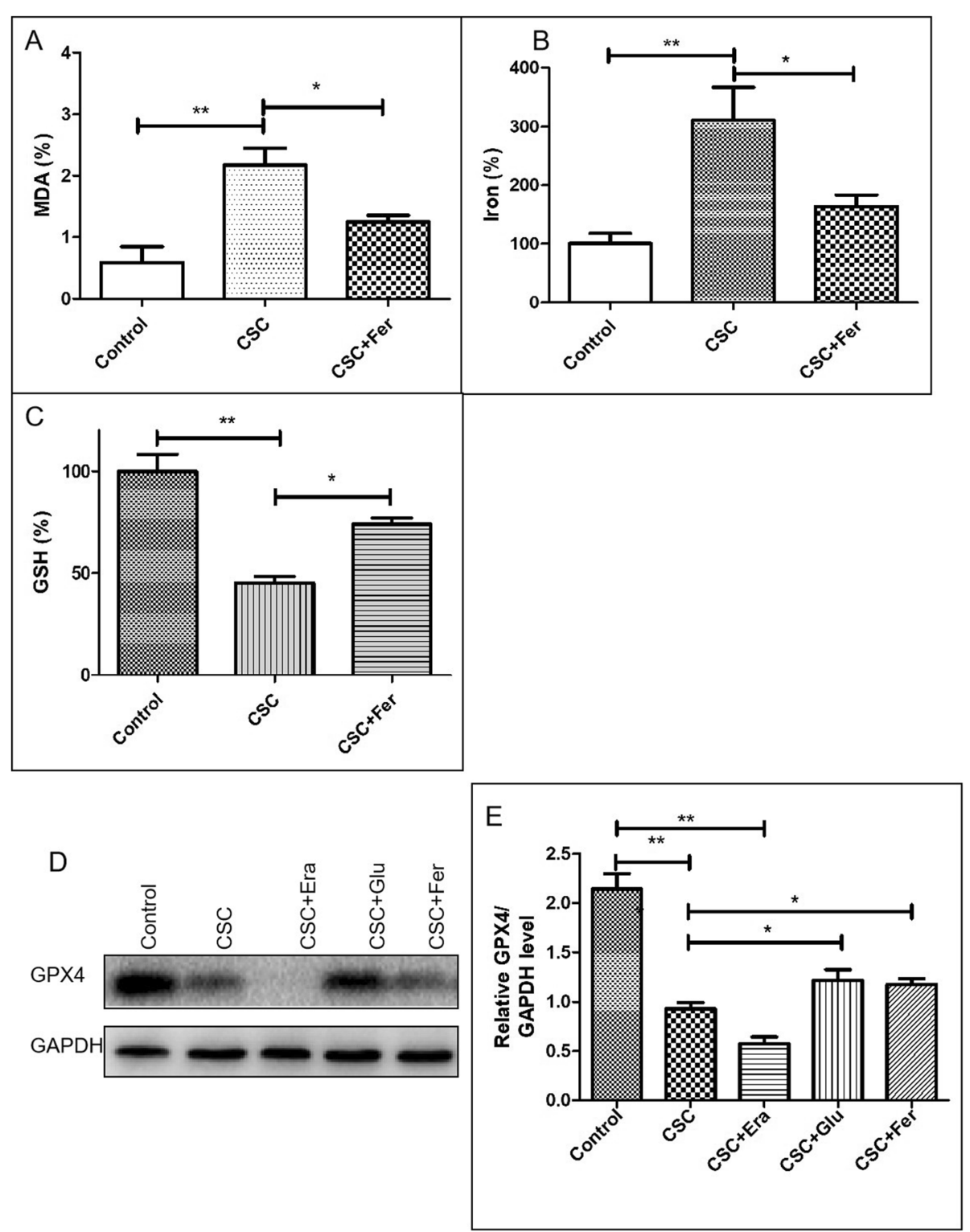

Fig. 3 GSH, lipid ROS and iron level in GC-2spd cells after CSC treatment. a Lipid ROS level in the GC-2spd cells after CSC treatment and after precultured with Fer-1. b Iron level in the GC-2spd cells after CSC treatment and after pre-cultured with Fer-1. c GSH level in the GC-2spd cells after CSC treatment and after pre-cultured with Fer-1. d, e GPX4 level in the GC-2spd cells after CSC treatment and after pre-cultured with Fer-1.*P $<$ 0.05 , ${ }^{* *} P<0.01$ represents the statistical difference compared to the respective group $(n=3)$

directly by compounds such as RSL3 [21, 23]. A variety of inhibitors and inducers of ferroptosis have been reported to regulate the accumulation of lethal lipid reactive oxygen species (ROS) derived from iron metabolism turbulence [22, 41]. In this study, the level of GPX4 protein and GSH level were reduced and the level of MDA and iron were increased. Reduced GSH serves a role in antioxidant defense, and the GSH-GPX4 interaction is critical for the regulation of redox [21]. Depletion of GSH, a basal cofactor of GPX, impairs GPX4 function which can lead to cellular redox state changes and ferroptosis [21]. But the mechanism of ferroptosis induction and the associated signaling pathway responsible for regulating cell death still needs to be further proven.

In conclusion, this study indicates that cigarette smoking is associated with high level of ferroptosis in seminal plasma and affects sperm quality. Accordingly, this finding may be used as a clinical basis for the development of new efficacious treatments for smokinginduced cell death and male infertility. 


\section{Abbreviations}

GSH: Glutathione; ROS: Lipid reactive oxygen species; GPX4: GSH-dependent peroxidase 4; CSC: Cigarette smoke condensate; ATCC: American Tissue Culture Collection; DMEM: Dulbecco modified Eagles media; CCK-8: Cell Counting Kit-8; MDA: Malondialdehyde; Fer-1: Ferrostatin-1; COPD: Chronic obstructive pulmonary disease

\section{Acknowledgements}

Not applicable.

\section{Authors' contributions}

$\mathrm{ZHO}$ developed the concept of the study; All authors contributed to data accumulation; ZHO, YD, ZHC, YY and QRW contributed to data analysis; ZHO and QRW performed the experiment; ZHO wrote the manuscript. All authors contributed to revisions of the manuscript, and approved of the final submission. ZHO takes responsibility for the accuracy of the data analysis.

\section{Funding}

This study was supported by institutional funding of Youth medicine research and development program for Reproductive Medicine from Chinese Medical Association (17020150684), Health Science and technology project of Guangzhou (20201A011029), Guangzhou Women and Children's Medical Center (Pre-NSFC-2016-006, 1600057-04) and National Natural Science Foundation of China (81800110)

\section{Availability of data and materials}

Data were obtained from the referenced publications. Further information is available by contacting Dr. Ou at zhanhui-ou@hotmail.com.

\section{Ethics approval and consent to participate}

The study has been approved by the Ethics Committee of our Institution (2017021201). Oral and written consent was obtained for all willing participants prior to registering for this study. Patient Informed consent to participate in this study. The authors have consented for publication.

\section{Competing interests}

The authors declare that they have no competing interests.

\section{Author details}

${ }^{1}$ Center of Reproductive Medicine, Guangzhou Women and Children's Medical Center, Guangzhou Medical University, 510623, Guangzhou, Guangdong, P.R. China. ²Department of Gynecological Oncology, Guangzhou Women and Children's Medical Center, Guangzhou Medical University, 510623, Guangzhou, Guangdong, P.R. China.

\section{Received: 4 March 2020 Accepted: 20 May 2020}

Published online: 27 May 2020

\section{References}

1. Bashamboo A, Ferraz-de-Souza B, Lourenço D, Lin L, Sebire NJ, Montjean D, Bignon-Topalovic J, Mandelbaum J, Siffroi J, Christin-Maitre S, Radhakrishna U, Rouba H, Ravel C, Seeler J, Achermann JC, McElreavey K. Human male infertility associated with mutations in NR5A1 encoding steroidogenic facto 1. Am J Hum Genet. 2010:87:505-12.

2. Auger J, Kunstmann JM, Czyglik F, Jouannet $P$. Decline in semen quality among fertile men in Paris during the past 20 years. N Engl J Med. 1995; 332:281-5

3. de Kretser DM. Male infertility, Lancet (London, England). 1997:349:787-90.

4. Vine MF. Worldwide decline in semen quality might be due to smoking. BMJ. 1996:312:506.

5. Anifandis G, Bounartzi T, Messini Cl, Dafopoulos K, Sotiriou S, Messinis IE. The impact of cigarette smoking and alcohol consumption on sperm parameters and sperm DNA fragmentation (SDF) measured by Halosperm. Arch Gynecol Obstet. 2014;290(4):777-82.

6. Yu B, Qi Y, Liu D, Gao X, Chen H, Bai C, Huang Z. Cigarette smoking is associated with abnormal histone-to-protamine transition in human sperm. Fertil Steril. 2014;101:51-7.

7. Trummer H, Habermann H, Haas J, Pummer K. The impact of cigarette smoking on human semen parameters and hormones. Hum Reprod. 2002; 17:1554-9.
8. Li Y, Lin H, Ma M, Li L, Cai M, Zhou N, Han X, Bao H, Huang L, Zhu C, Li C, Yang H, Rao Z, Xiang Y, Cui Z, Ao L, Zhou Z, Xiong H, Cao J. Semen quality of 1346 healthy men, results from the Chongqing area of southwest China. Hum Reprod. 2009:24:459-69.

9. Aryanpur M, Tarahomi M, Sharifi H, Heydari G, Hessami Z, Akhoundi M, Masjedi MR. Comparison of spermatozoa quality in male smokers and nonsmokers of Iranian infertile couples. Int J Fertil Steril. 2011;5:152-7.

10. Al-Matubsi HY, Kanaan RA, Hamdan F, Salim M, Oriquat GA, Al Hanbali OA. Smoking practices in Jordanian people and their impact on semen quality and hormonal levels among adult men. Cent Eur J Public Health. 2011;19:54-9.

11. Li Y, Lin H, Li Y, Cao J. Association between socio-psycho-behavioral factors and male semen quality: systematic review and meta-analyses. Fertil Steril. 2011;95:116-23.

12. Martini AC, Molina RI, Estofán D, Senestrari D, Fiol De Cuneo M, Ruiz RD. Effects of alcohol and cigarette consumption on human seminal quality. Fertil Steril. 2004;82:374-7.

13. Sergerie M, Ouhilal S, Bissonnette F, Brodeur J, Bleau G. Lack of association between smoking and DNA fragmentation in the spermatozoa of normal men. Hum Reprod. 2000;15:1314-21.

14. Pryor WA, Stone K, Zang LY, Bermúdez E. Fractionation of aqueous cigarette tar extracts: fractions that contain the tar radical cause DNA damage. Chem Res Toxicol. 1998;11:441-8.

15. Zang $L Y$, Stone $K$, Pryor WA. Detection of free radicals in aqueous extracts of cigarette tar by electron spin resonance. Free Radic Biol Med. 1995;19: $161-7$.

16. Yu B, Chen J, Liu D, Zhou H, Xiao W, Xia X, Huang Z. Cigarette smoking is associated with human semen quality in synergy with functional NRF2 polymorphisms. Biol Reprod. 2013;89:5.

17. Ramlau-Hansen CH, Thulstrup AM, Aggerholm AS, Jensen MS, Toft G, Bonde JP. Is smoking a risk factor for decreased semen quality? A cross-sectional analysis. Hum Reprod. 2007;22:188-96.

18. Künzle R, Mueller MD, Hänggi W, Birkhäuser $M H$, Drescher $H$, Bersinger NA. Semen quality of male smokers and nonsmokers in infertile couples. Fertil Steril. 2003;79:287-91.

19. Vine MF, Margolin BH, Morrison HI, Hulka BS. Cigarette smoking and sperm density: a meta-analysis. Fertil Steril. 1994;61:35-43.

20. Dixon SJ, Lemberg KM, Lamprecht MR, Skouta R, Zaitsev EM, Gleason CE, Patel DN, Bauer AJ, Cantley AM, Yang WS, Morrison BR, Stockwell BR. Ferroptosis: an iron-dependent form of nonapoptotic cell death. Cell. 2012; 149:1060-72.

21. Yang WS, Stockwell BR. Ferroptosis: death by lipid peroxidation. Trends Cell Biol. 2016;26:165-76

22. Xie Y, Hou W, Song X, Yu Y, Huang J, Sun X, Kang R, Tang D. Ferroptosis: process and function. Cell Death Differ. 2016;23:369-79.

23. Hayano M, Yang WS, Corn CK, Pagano NC, Stockwell BR. Loss of cysteinyl-tRNA synthetase (CARS) induces the transsulfuration pathway and inhibits ferroptosis induced by cystine deprivation. Cell Death Differ. 2016;23:270-8

24. Yang WS, Stockwell BR. Synthetic lethal screening identifies compounds activating iron-dependent, nonapoptotic cell death in oncogenic-RASharboring cancer cells. Chem Biol. 2008;15:234-45.

25. Wang H, An P, Xie E, Wu Q, Fang X, Gao H, Zhang Z, Li Y, Wang X, Zhang J, Li G, Yang L, Liu W, Min J, Wang F. Characterization of ferroptosis in murine models of hemochromatosis. Hepatology. 2017;66:449-65.

26. Guiney SJ, Adlard PA, Bush Al, Finkelstein DI, Ayton S. Ferroptosis and cell death mechanisms in Parkinson's disease. Neurochem Int. 2017;104:34-48.

27. Sun X, Ou Z, Chen R, Niu X, Chen D, Kang R, Tang D. Activation of the p62Keap1-NRF2 pathway protects against ferroptosis in hepatocellular carcinoma cells. Hepatology. 2016;63:173-84.

28. Bromfield EG, Walters JLH, Cafe SL, Bernstein IR, Stanger SJ, Anderson AL, Aitken RJ, McLaughlin EA, Dun MD, Gadella BM, Nixon B. Differential cell death decisions in the testis: evidence for an exclusive window of ferroptosis in round spermatids. Mol Hum Reprod. 2019;25:241-56.

29. World Health Organization. WHO laboratory manual for the examination and processing of human semen. 5th ed. Geneva: World Health Organization press; 2010.

30. Ou Z, Chen Y, Niu X, He W, Song B, Fan D, Sun X. High-mobility group box 1 regulates cytoprotective autophagy in a mouse spermatocyte cell line (GC-2spd) exposed to cadmium. Ir J Med Sci. 2017;186:1041-50.

31. Liu F, Killian JK, Yang M, Walker RL, Hong JA, Zhang M, Davis S, Zhang Y, Hussain M, Xi S, Rao M, Meltzer PA, Schrump DS. Epigenomic alterations 
and gene expression profiles in respiratory epithelia exposed to cigarette smoke condensate. Oncogene. 2010;29:3650-64.

32. Sun X, Ou Z, Xie M, Kang R, Fan Y, Niu X, Wang H, Cao L, Tang D. HSPB1 as a novel regulator of ferroptotic cancer cell death. Oncogene. 2015;34:5617-25.

33. Barnes PJ. Chronic obstructive pulmonary disease. N Engl J Med. 2000;343: 269-80.

34. Parkin DM, Bray F, Ferlay J, Pisani P. Global cancer statistics, 2002. CA Cancer J Clin. 2005;55:74-108

35. Taha EA, Ez-Aldin AM, Sayed SK, Ghandour NM, Mostafa T. Effect of smoking on sperm vitality, DNA integrity, seminal oxidative stress, zinc in fertile men. Urology. 2012;80:822-5.

36. Calogero A, Polosa R, Perdichizzi A, Guarino F, La Vignera S, Scarfia A, Fratantonio E, Condorelli R, Bonanno O, Barone N, Burrello N, D'Agata R, Vicari E. Cigarette smoke extract immobilizes human spermatozoa and induces sperm apoptosis. Reprod BioMed Online. 2009:19:564-71.

37. Li L, Hao Y, Zhao Y, Wang H, Zhao X, Jiang Y, Gao F. Ferroptosis is associated with oxygen-glucose deprivation/reoxygenation-induced Sertoli cell death. Int J Mol Med. 2018;41:3051-62.

38. El-Seweidy MM, Hashem RM, Abo-El-matty DM, Mohamed RH. Frequent inadequate supply of micronutrients in fast food induces oxidative stress and inflammation in testicular tissues of weanling rats. J Pharm Pharmacol. 2008:60:1237-42.

39. Sundarraj K, Manickam V, Raghunath A, Periyasamy M, Viswanathan MP, Perumal E. Repeated exposure to iron oxide nanoparticles causes testicular toxicity in mice. Environ Toxicol. 2017;32:594-608.

40. Martin-Sanchez D, Ruiz-Andres O, Poveda J, Carrasco S, Cannata-Ortiz P, Sanchez-Niño MD, Ruiz Ortega M, Egido J, Linkermann A, Ortiz A, Sanz AB. Ferroptosis, but not Necroptosis, is important in nephrotoxic folic acidinduced AKI. J Am Soc Nephrol. 2017;28:218-29.

41. Cao JY, Dixon SJ. Mechanisms of ferroptosis. Cell Mol Life Sci. 2016;73:2195209

\section{Publisher's Note}

Springer Nature remains neutral with regard to jurisdictional claims in published maps and institutional affiliations.

Ready to submit your research? Choose BMC and benefit from:

- fast, convenient online submission

- thorough peer review by experienced researchers in your field

- rapid publication on acceptance

- support for research data, including large and complex data types

- gold Open Access which fosters wider collaboration and increased citations

- maximum visibility for your research: over $100 \mathrm{M}$ website views per year

At $\mathrm{BMC}$, research is always in progress.

Learn more biomedcentral.com/submissions 